\title{
BMJ Open Facilitators and barriers to safer care in Scottish general practice: a qualitative study of the implementation of the trigger review method using normalisation process theory
}

\author{
Carl de Wet, ${ }^{\oplus 1}$ Paul Bowie, ${ }^{2}$ Catherine A O'Donnell ${ }^{3}$
}

To cite: de Wet C, Bowie $P$, 0 'Donnell CA. Facilitators and barriers to safer care in Scottish general practice: a qualitative study of the implementation of the trigger review method using normalisation process theory. BMJ Open 2019;9:e029914. doi:10.1136/ bmjopen-2019-029914

- Prepublication history and additional material for this paper are available online. To view these files, please visit the journal online (http://dx.doi. org/10.1136/bmjopen-2019029914).

Received 20 February 2019 Revised 22 August 2019 Accepted 23 August 2019

Check for updates

(C) Author(s) (or their employer(s)) 2019. Re-use permitted under CC BY-NC. No commercial re-use. See rights and permissions. Published by BMJ.

${ }^{1}$ School of Medicine, Griffith University, Gold Coast, Queensland, Australia 2Patient Safety Research, NHS Education for Scotland, Glasgow, UK

${ }^{3}$ General Practice and Primary Care, University of Glasgow, Glasgow, UK

Correspondence to

Dr Carl de Wet;

carl_dewet@yahoo.co.uk

\section{ABSTRACT}

Objectives Patient safety is a key concern of modern health systems, with numerous approaches to support safety. One, the trigger review method (TRM), is promoted nationally in Scotland as an approach to improve the safety of care in general medical practice. However, it remains unclear which factors are facilitating or hindering its implementation. The aim of this study was to identify the important factors that facilitate or hinder the implementation of the TRM in this setting.

Design Qualitative study employing semi-structured interviews. Data analysis was theoretically informed using normalisation process theory (NPT).

Setting Scottish general practice.

Participants We conducted 28 semistructured interviews with general practitioners $(n=12)$, practice nurses $(n=11)$ and practice managers $(n=5)$ in Scotland.

Results We identified four important factors that facilitated or hindered implementation: (1) the amount of time and allocated resources; (2) integration of the TRM into existing initiatives and frameworks facilitated implementation and justified participants' involvement; (3) the characteristics of the reviewers-implementation was facilitated by experienced, reflective clinicians with leadership roles in their teams; (4) the degree to which participants perceived the TRM as acceptable, feasible and useful.

Conclusions This study is the first known attempt to investigate how the TRM is implemented and perceived by general practice clinicians and staff. The four main factors that facilitated TRM implementation are comparable with the wider implementation science literature, suggesting that a small number of specific factors determine the success of most, if not all, complex healthcare interventions. These factors can be identified, described and understood through theoretical frameworks such as NPT and are amenable to intervention. Researchers and policymakers should proactively identify and address these factors.

\section{INTRODUCTION}

Patient safety is a key concern of modern healthcare systems. ${ }^{1}$ The importance of patient safety first emerged in the hospital
Strengths and limitations of this study

- The convenience sample was a pragmatic choice and may not be representative of general practice in Scotland or the UK.

- The trigger review method were considered from the perspective of general practitioners, practice managers and nurses-the three staff groups that were critical to its successful implementation.

- A validated theoretical framework was used to analyse the data.

- Analysis was emergent and exploratory, and data were not 'shoe-horned' into the normalisation process theory framework.

Thematic saturation was achieved.

setting, due to the possibility of errors leading to patient death and disability. ${ }^{2}{ }^{3}$ However, patient safety is increasingly an area of concern in primary care. ${ }^{45}$ In the UK, patient safety incidents (PSIs) have been defined as 'any unintended or unexpected incident which could have or did lead to harm for one of more patients receiving National Health Service (NHS) care' ${ }^{6}$ There is, however, a recognised difficulty in identifying and measuring PSIs and many remain undetected. ${ }^{7}$ This has led to variation in the estimation of PSIs in primary care, ranging from $<1$ to 24 PSIs per 100 consultations. ${ }^{4}$ While this may be lower than that reported for hospital care, the volume of consultations that take place in primary care (eg, over 340 million general practice consultations in England in 2013) equates to the opportunity for substantial harm for $\sim 300000$ patients each year. ${ }^{8}$ This has increased the urgency and effort with which policymakers, healthcare leaders, clinicians and researchers have responded. ${ }^{9}$ Programme, initiatives and interventions aiming to identify safety threats, 
reliably reduce ameliorable risks and measurably improve healthcare performance have proliferated, including in the NHS of the UK. Examples include the Department of Health's Patient Safety Research Portfolio and the Safer Patients Initiative and Safer Patients Network of the Health Foundation, a large and independent charity committed to bringing about better health in the UK. ${ }^{10-12}$

In Scotland, a national patient safety programme (SPSP) was launched in 2008 with the ambitious aims of significantly reducing secondary care mortality and harm. ${ }^{13}$ As the programme became established in hospitals, it was expanded into primary care (SPSP-PC), beginning with general medical practice. ${ }^{14}$ The SPSP-PC aimed to measurably improve the safety of care provided in participating practices through three different strategies that were specifically developed or adapted for this purpose. ${ }^{15}$ They were (1) detecting, learning from and reducing PSIs by applying the trigger review method (TRM); $;^{17}$ (2) measuring and building a strong and positive safety culture $;{ }^{18}$ and (3) improving chronic disease and medication management by using a care bundle approach. ${ }^{19}$ All three methods have been the focus of research in different international healthcare settings, which have increased our understanding of their potential usefulness as interventions to improve patient safety. ${ }^{20-24}$ However, much remains unknown, including which factors are associated with their successful implementation or lack thereof.

The TRM is essentially an adaptation of clinical record review (CRR) or 'case note audit', providing a structured way to rapidly screen samples of random electronic patient records for undetected PSIs. CRR is a well-established approach of detecting and quantifying suboptimal care issues and is considered the gold standard in epidemiological type patient safety research. ${ }^{25}$ The key strength of CRR compared with other approaches is that it detects a significantly greater proportion of all PSIs. ${ }^{26}$ This is why the original landmark studies about the prevalence of adverse events in hospitals in the USA, ${ }^{27}$ UK, ${ }^{2}$ Australia, ${ }^{28}$ Canada $^{29}$ and New Zealand ${ }^{30}$ all used some form of CRR adapted to their settings and purposes. ${ }^{26}$

Development of the TRM commenced in 2007 in Scottish general practice, with subsequent testing in The Health Foundation-funded Safety and Improvement in Primary Care programme. ${ }^{1516}$ In 2013, the TRM was added to the quality and outcomes framework (QOF) of the UK general medical services contract (described in box 1) with the expectation that it would be implemented nationally by Scottish general practices (c1000). A subsequent study of the implementation of the TRM found that most clinicians uncovered important patient safety concerns in their individual practices and took specific actions to improve the related care systems and processes. ${ }^{20}$ A description of the intended application of the TRM and a clinical example of its potential value are provided in boxes 2 and 3 respectively.

Developing a potentially useful, complex healthcare intervention like the TRM is challenging. However,
Box 1 Summary of the quality and outcomes framework (QOF)

The QOF was a major component of the general medical services (GMS) contract between UK general practices and the National Health Service. ${ }^{65}$ It was introduced in April 2004 to help address longstanding variation in the quality of primary care provision. ${ }^{66}$ The QOF was the largest pay-for-performance scheme in international healthcare and one of the most important, influential but also controversial initiatives ever to be implemented in UK general practice. The QOF measured participating practices' performances annually against a range of evidence-based or preagreed 'point-in-time' indicators. Practices 'earned' points according to their level of achievement for each indicator, with payment starting at a minimum threshold (usually $40 \%$ ) rising to a maximum (usually $90 \%$ ). Points were weighted according to the practice list size and were worth from tens to hundreds of pounds each. Participation in the QOF was voluntary, but the reality was that most practices would not have been viable business concerns if they had opted out. Consequently, virtually all Scottish general practices with GMS contracts participated in the QOF as it was one of their main potential sources of income. QOF was decommissioned in Scotland in April $2016^{67}$ and replaced, in part, with general practitioner clusters - groups of 6-8 practices with practice quality leads and a cluster quality lead who are responsible for assessing, managing and improving care quality. ${ }^{57}$

successfully implementing that intervention, sustaining its use and embedding it into routine practice are arguably even greater challenges. ${ }^{31}{ }^{32}$ Understanding the implementation of such interventions, including a clear explication of the barriers and facilitators to implementation, could prevent considerable amounts of time, effort and resources from being squandered. Despite the TRM being promoted and implemented in general practice nationally across Scotland, it remains unclear which factors are facilitating or hindering the success or otherwise of this process, and their relative importance in determining whether, or to what degree, this intervention can be integrated into routine practice. The aim of this study, therefore, was to identify the important contextual, organisational and resource factors that facilitated or hindered the implementation of the TRM in Scottish general medical practice. A theoretical framework was used to underpin the data collection, analysis and interpretation of the findings.

\section{Use of theory to understand the implementation of patient safety initiatives}

It is now accepted that the application of a theoretical lens can greatly enhance our understanding of the organisational and contextual factors which influence the implementation of quality improvement (QI) and patient safety initiatives. ${ }^{33-35}$ The Medical Research Council guidelines recommend the explicit application of theory from the earliest stages of designing and implementing complex healthcare interventions, such as the TRM, to reduce the likelihood that important factors will be overlooked. ${ }^{36} 37$ There are two reasons for this. First, complex interventions such as the TRM are often a 'black box', with a lack of clarity about which elements are implemented well, 
Box 2 Practical application of the trigger review method (TRM) in general practice

The TRM allows clinicians, for example, general practitioners (GPs), GP registrars and practice nurses, to screen samples of patient records $(n= \pm 25)$ from their own practice for previously undetected patient safety incidents (PSIs) in a structured, focused, rapid and active manner:

- Structured - each of the five sections of a primary care record are screened in turn. The five sections are: clinical encounters; medication; clinical codes; correspondence; and investigations.

- Focused-reviewers search for predefined 'triggers'. Triggers are prompts, sentinel phrases or 'signs' in the record that may indicate the occurrence of PSIs.

- Rapid - a maximum of 20 min is allocated per record and only a prespecified period in each record is reviewed (three calendar months).

- Active-clinicians are encouraged to reconstruct each patient journey and probe, analyse and critically appraise the record for evidence of PSIs and latent risks hidden in it.

Clinicians record their findings, reflections and actions on a 'Trigger Review Summary Sheet' (SS). The SS is a double-sided template for collecting and summarising data on the number of detected triggers, the details of any PSIs uncovered, any learning needs identified and actions that were or should be taken because of the review process. Clinicians are encouraged to share the findings from the trigger reviews with their practice team and to involve them in subsequent improvement actions.

The TRM has three consecutive steps: (1) planning and preparation; (2) review of records; and (3) reflection and action. Practice managers and non-clinical staff are involved in steps 1 and 3 but do not perform trigger reviews (step 2). In our experience, clinical reviewers require on average 2-3hours of protected time to apply the method and perform a 'trigger review' effectively. Two trigger reviews per year seems to be generally acceptable and feasible. Clinicians should receive 1-2 hours of training individually or in groups before they apply the TRM for the first time. Training is flexible but included as a minimum: a short presentation about the TRM; opportunities to practice trigger reviews using simulated patient records with facilitation and real-time feedback and provision of an educational support package.

Box 3 Example of the potential value of the trigger review method

While screening a sample of patient records $(n=25)$, GP03 identified an elderly patient with established chronic kidney disease (CKD) who had not been added to the practice register and had not been offered the recommended Angiotensin II receptor blockers (ARBs) treatment. She recorded the patient safety incident (PSI) (suboptimal treatment of a patient with CKD) on the trigger review SS and rated it as low severity and high preventability. GP03 expressed surprise at detecting this PSI because the patient had consulted with her on several previous occasions in the preceding months. She described how her first actions had been to add him to the relevant chronic disease register, request a repeat eGFR blood test to check his renal function and that she arranged a review appointment to monitor his blood pressure and discuss potential further treatment. While reflecting on this incident, she identified a professional learning need about the management of CKD and subsequently addressed it. The incident was also discussed during a practice meeting and the team decided to update the practice protocol for the management of CKD and to perform a clinical audit to measure and improve the management of their patients with CKD. and why. ${ }^{34}$ Second, such complex interventions are implemented in a dynamic and ongoing social context, shaped by the actors using them and by the wider organisational and socio-cultural structures into which the intervention-in this case the TRM-is placed. ${ }^{38} 39$

Selecting the most suitable theory from the large, complex and diverse range of options can then be informed by the specific requirements of the study and researchers. ${ }^{40}{ }^{41}$ As this study was principally concerned with the 'work' that practitioners had to do to implement the TRM, both as individuals and collectively in practices, and how that interacted with their work-based context, we selected normalisation process theory (NPT) as our theoretical framework. NPT is a sociotechnical, middlerange theory about the work people do collectively and as individuals to implement and sustain an intervention. It has been successfully used in multiple studies and international healthcare settings and is particularly useful for describing, understanding and evaluating complex healthcare interventions such as the TRM. ${ }^{42-44}$

The NPT framework consists of four main 'constructs'. ${ }^{45}$ They are:

1. Coherence-the work implementers do to understand an intervention.

2. Cognitive participation-the relational work to build a community of practice around an intervention.

3. Collective action-the operational work of enacting an intervention.

4. Reflexive monitoring - the work of assessing and reconfiguring an intervention.

Each construct is divided further into four components, which promotes a nuanced understanding of the implementation process. The NPT constructs and components and how they relate to the TRM are described in table 1 .

\section{METHODS}

\section{Study design}

Qualitative study employing semi-structured interviews with general practitioners (GPs), practice nurses (PNs) and practice managers (PMs). A range of different types of general practice staff was included in the study to allow exploration and comparison of the perceptions of clinicians and non-clinicians and practice owners or partners and salaried employees. We used the standards for reporting qualitative research checklist for the study and manuscript. ${ }^{46}$

\section{Setting and sample}

In Scotland, the organisational structure of the publicly funded NHS consists of 14 regional 'Boards' who are responsible for the delivery of frontline health services and improving the health of the populations resident in their respective geographical areas. ${ }^{47}$ This study was undertaken in the West of Scotland in two of the Boards: one covering a large, urban setting with 262 general practices (designated Health Board A); the other covering a mixed urban-rural setting, with 56 practices (Health 
Table 1 The NPT framework in relation to the TRM

\begin{tabular}{lll}
\hline Constructs & Components & Description \\
\hline Coherence & $\begin{array}{l}\text { Differentiation } \\
\text { Communal } \\
\text { specification } \\
\begin{array}{l}\text { Individual } \\
\text { specification } \\
\text { Internalisation }\end{array}\end{array}$ & $\begin{array}{l}\text { The work to understand the TRM } \\
\text { The work participants do to understand the differences and similarities between the TRM } \\
\text { and other Ql methods }\end{array}$ \\
\hline $\begin{array}{l}\text { The work required to understand the purpose and potential benefits of the TRM } \\
\text { feasible and a priority? }\end{array}$ \\
$\begin{array}{l}\text { The work individuals and teams did to understand how the TRM 'fits in' with their culture } \\
\text { and existing work. Is it acceptable? }\end{array}$
\end{tabular}

\begin{tabular}{|c|c|}
\hline Cognitive participation & The relational work required to build and sustain a community of practice around the TRM \\
\hline Initiation & The work of ensuring that staff and clinicians are willing and able to use the TRM \\
\hline Enrolment & $\begin{array}{l}\text { The work of identifying and recruiting the necessary people and ensuring the remain } \\
\text { engaged in the process }\end{array}$ \\
\hline Activation & $\begin{array}{l}\text { The continuing support work that is necessary to disseminate trigger review findings, } \\
\text { create opportunities for improvement and sustain the use of the TRM }\end{array}$ \\
\hline Legitimation & $\begin{array}{l}\text { The work individuals and teams do to justify their involvement with the TRM to } \\
\text { themselves and others }\end{array}$ \\
\hline
\end{tabular}

\begin{tabular}{|c|c|}
\hline Collective action & The operational work required to enact the TRM. It requires participants to invest effort \\
\hline $\begin{array}{l}\text { Interactional } \\
\text { workability }\end{array}$ & $\begin{array}{l}\text { The work of applying the TRM, the time and effort this required and the outcomes, that is, } \\
\text { whether and what type of PSIs they detected and the subsequent improvement actions } \\
\text { they took }\end{array}$ \\
\hline Relational integration & $\begin{array}{l}\text { The work of building confidence in the TRM, their own and colleagues' abilities to } \\
\text { effectively apply it and trust that the findings are accurate }\end{array}$ \\
\hline Skill-set workability & $\begin{array}{l}\text { The work of dividing tasks, allocating resources and assessing the skills of the available } \\
\text { team members }\end{array}$ \\
\hline $\begin{array}{l}\text { Contextual } \\
\text { integration }\end{array}$ & $\begin{array}{l}\text { The work of integrating the TRM into existing structures, contexts and policies. It includes } \\
\text { allocation of adequate resources and leadership support of the TRM }\end{array}$ \\
\hline Reflexive monitoring & The work of assessing and appraising the individual and communal worth of the TRM \\
\hline Systemisation & The work of collecting and analysing data about the TRM \\
\hline Individual appraisal & $\begin{array}{l}\text { The work of evaluating the value (usefulness, worth) of the TRM for the clinician reviewer, } \\
\text { her practice and patients }\end{array}$ \\
\hline Communal appraisal & The work of evaluating the value of the TRM for other practices and their patients \\
\hline Reconfiguration & The work of adapting the TRM, team or contexts \\
\hline
\end{tabular}

NPT, normalisation process theory; PSIs, patient safety incidents; QI, quality improvement; TRM, trigger review method.

Board B). In April 2012, all PMs in each board area were sent written information via email about the proposed study and an invitation for the PM and at least one GP and a PN to receive TRM training (box 2) and participate. Due to resource constraints, recruitment stopped when 12 practices had agreed to participate. A convenience sample of GP practices was constructed to reflect the relative numerical distribution: 10 practices from board A and 2 from board B.

\section{Patient and public involvement}

Patients and the public were not involved in the design or planning of this study.

\section{Data collection}

The interview schedule was derived from the NPT framework and agreed by the authors (online supplementary appendix 1). The interviews were conducted in the practice premises of participants at a time convenient to them. Informed consent was obtained from study participants prior to the interviews being conducted and after the purpose of the interview had been explained and anonymity assured. All interviews were conducted by the same investigator (CdW) who introduced himself as a GP and a researcher and explained that the interviews were confidential, candid and participants had no obligation to report 'successes' 
with the TRM or the implementation process. Interviews were conducted between January 2013 and July 2013 and lasted $\sim 45 \mathrm{~min}$. They were digitally recorded and supplemented with contemporaneous field notes.

\section{Data analysis}

All interviews were transcribed verbatim to preserve colloquialisms, repetition and other non-verbal communication that could aid data interpretation but were not reviewed by participants. Transcripts were anonymised and the twelve participating practices assigned a unique identifier. This identifier was applied to every participant within a given practice. Participants from the same practice were differentiated by adding a further, unique identifier as a prefix, derived from their professional role: GP, PN and PM.

Data coding was led by CdW and CAO and was informed by a framework approach using a coding frame informed by NPT. ${ }^{48}$ First, data were coded broadly to one of the four main NPT constructs. Following this, data were coded in greater detail to the specific NPT components of each construct; for example, data pertaining to understanding of the TRM (coherence) were then reread and further coded to the subconstructs of differentiation, communal or individual specification and internalisation. Data could be double-coded to more than one subconstruct. The codes were then analysed in conjunction with the related, reflective memos to interpret the emerging views and themes and compare the perceptions of the different staff groups. The codes and themes were mapped and displayed using NVivo V.9.2.81.0. All authors met regularly to discuss the findings, ensure consistency and agree and verify data interpretations.

Care was taken, however, to ensure that the analysis was emergent and exploratory, and that data were not 'shoe-horned' into the NPT framework. Data that fell out with the NPT framework were assigned stand-alone codes and analysed separately to this study. The authors recognised, for example, that some data described how the TRM influenced participants and outcomes, rather than the work of implementation, and therefore assigned different codes such as 'patient safety mindset' and 'learning moments' (unpublished-available on request from the corresponding author).

\section{RESULTS}

Demographic data from the participating practices are summarised in table 2. A total of 28 interviews were conducted with GPs $(n=12)$, PNs $(n=11)$ and PMs $(n=5)$. One practice did not have a nurse during the study period, two PMs had to withdraw from the study due to unexpected personal reasons and another practice had a practice nurse (PN01) with the dual role of PM. The PMs of the remaining four practices were willing to be interviewed but were excluded because concurrent data analysis indicated that data saturation was achieved as no new data or insights were obtained from the last few interviews.

The Results section is structured according to the four main constructs of the NPT framework. The study findings relating to each construct is described in the text and summarised as a table with selected, verbatim quotes. The four NPT constructs are: coherence (table 3), cognitive participation (table 4), collective action (table 5) and reflexive monitoring (table 6).

Coherence: the work individuals and teams did to understand the TRM

Many participants explained their understanding of the TRM by comparing it with other QI methods they were

Table 2 Demographic data of the participating practices

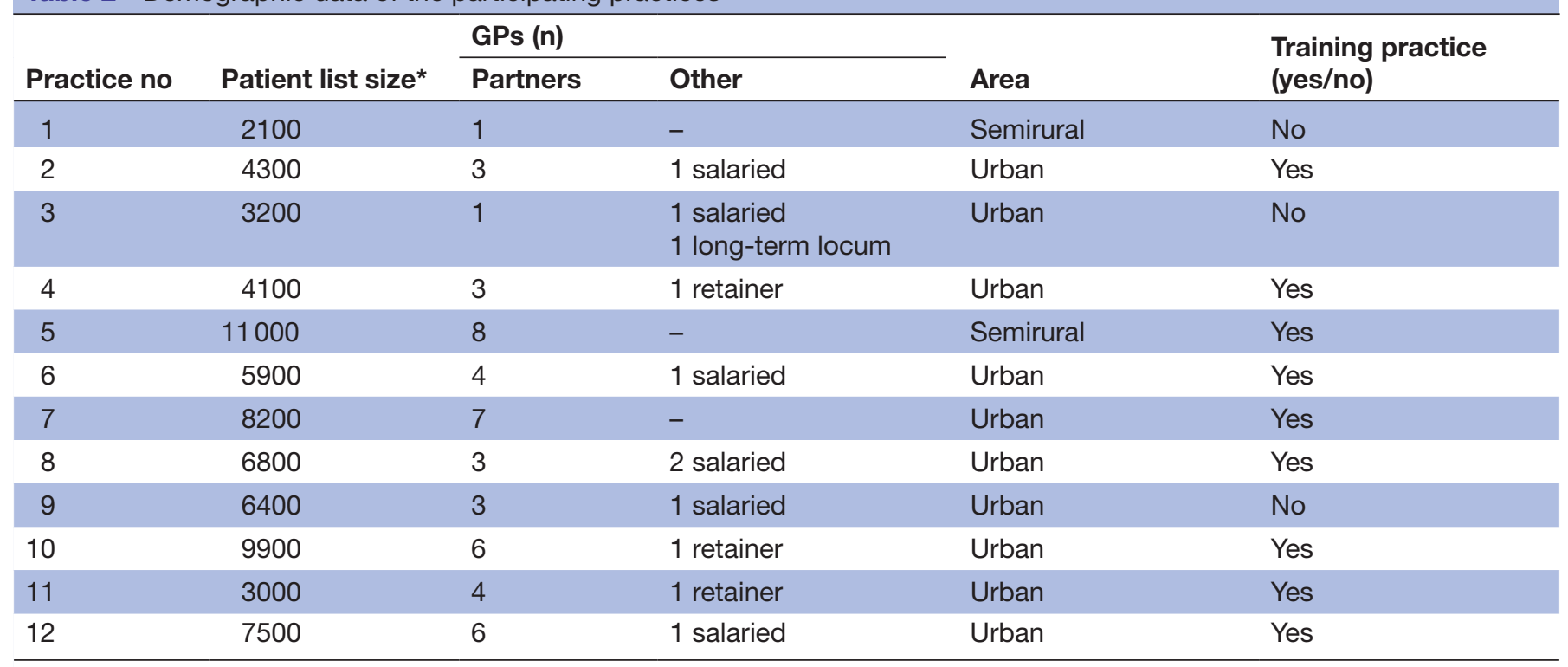

${ }^{*}$ Rounded to the nearest hundred at the beginning of the study period.

GPs, general practitioners. 
Table 3 Coherence factors that facilitated or hindered TRM implementation

\begin{tabular}{|c|c|c|}
\hline NPT components & Factors & Selected verbatim quotes \\
\hline Differentiation & $\begin{array}{l}\text { Implementation was facilitated when respondents } \\
\text { understood the TRM was a new QI approach, but } \\
\text { complementary to existing methods such as clinical } \\
\text { audit or significant event analysis (SEA). }\end{array}$ & $\begin{array}{l}\text { [The TRM] is essentially looking to pick up an SEA } \\
\text { I suppose. That's the way that you could look at } \\
\text { it-if you need an SEA that's a good way to find } \\
\text { one' (GP07). }\end{array}$ \\
\hline $\begin{array}{l}\text { Communal } \\
\text { specification }\end{array}$ & $\begin{array}{l}\text { When participants understood the TRM's intended } \\
\text { aims and potential benefits they were more likely to } \\
\text { use it and achieve positive outcomes. }\end{array}$ & $\begin{array}{l}\text { 'I think it's useful as a learning tool to learn about } \\
\text { your own systems and a way of trying to improve } \\
\text { those systems and a way of learning as a team } \\
\text { with the results' (GP05). }\end{array}$ \\
\hline $\begin{array}{l}\text { Individual } \\
\text { specification }\end{array}$ & $\begin{array}{l}\text { All participants were concerned that the available } \\
\text { time and resources would be insufficient to } \\
\text { implement the TRM. However, the vast majority } \\
\text { found the TRM to be feasible, which then facilitated } \\
\text { its further use. }\end{array}$ & $\begin{array}{l}\text { I think the first time doing the first couple of } \\
\text { patients was a bit slow and because it's different } \\
\text { and you're not quite sure where you're at. So } \\
\text { it took a wee while, a couple of patients really } \\
\text { to get into the swing of it. I did it again just last } \\
\text { week and found it very quick and very easy to go } \\
\text { through (GP02). }\end{array}$ \\
\hline
\end{tabular}

NPT, normalisation process theory; QI, quality improvement; TRM, trigger review method.

already familiar with through QOF, such as clinical audit and significant event analysis (SEA) (table 3). However, despite the similarities between the TRM and other QI methods, participants also recognised sufficient differences for it to be perceived as a 'new' method.

Most participants initially expressed concerns that implementing the TRM would increase their workload and require additional resources and time. This perception was moderated as their understanding of the TRM increased by implementing it and they realised that the actual workload and time requirements were lower than they initially expected. For example, GP02 described getting 'bogged down' during the first trigger review but learnt from this experience and was able to apply the method more efficiently the second time. Most reviewers found the second trigger reviews quicker and easier, even though this did not necessarily mean the findings were more important or helpful.

Table 4 Cognitive participation factors that facilitated or hindered TRM implementation

\begin{tabular}{|c|c|c|}
\hline NPT components & Factors & Selected verbatim quotes \\
\hline Initiation & $\begin{array}{l}\text { Training sessions and access to expert support } \\
\text { facilitated implementation. However, training had to be } \\
\text { flexible and fit with the practices' needs. }\end{array}$ & $\begin{array}{l}\text { 'I've been trying to start the ground level } \\
\text { approach of saying 'this is how it should be } \\
\text { used', you know, used formatively and using it to } \\
\text { look at your systems as well, and things like that' } \\
\text { (GP05). }\end{array}$ \\
\hline Enrolment & $\begin{array}{l}\text { Initial recruitment of volunteers facilitated } \\
\text { implementation. However, most practice nurses } \\
\text { were assigned the TRM, which initially reduced the } \\
\text { motivation of some. }\end{array}$ & $\begin{array}{l}\text { Sometimes you know that, although they're } \\
\text { asking you [pause] it's going to come your way } \\
\text { anyway (PN09). }\end{array}$ \\
\hline Activation & $\begin{array}{l}\text { The TRM was facilitated when findings were } \\
\text { disseminated, and reviewers had sufficient autonomy } \\
\text { and opportunity to enact change. }\end{array}$ & $\begin{array}{l}\text { I wasn't involved at all (PM10). } \\
\text { I held a practice meeting afterwards to highlight } \\
\text { that perhaps we aren't always that good (GP06). }\end{array}$ \\
\hline Legitimation & $\begin{array}{l}\text { Implementation of the TRM was facilitated when } \\
\text { individuals and practice teams were able to justify } \\
\text { investing time and resources in its application. }\end{array}$ & $\begin{array}{l}\text { 'I'm not sure if I'd have gone back to [the TRM] } \\
\text { if it had disappeared off the horizon... you have } \\
\text { to justify the time in order to make it happen' } \\
\text { (GP06). } \\
\text { I feel I always have to justify every single working } \\
\text { minute I have in here (PN10). }\end{array}$ \\
\hline
\end{tabular}

NPT, normalisation process theory; TRM, trigger review method. 
Table 5 Collective action factors that facilitated or hindered TRM implementation

\begin{tabular}{|c|c|c|}
\hline NPT components & Factors & Selected verbatim quotes \\
\hline Relational integration & $\begin{array}{l}\text { Participants had confidence in the TRM but felt } \\
\text { unsure whether all other practices would apply it } \\
\text { correctly. A minority of clinicians were concerned } \\
\text { that the findings may be inappropriately } \\
\text { interpreted or used. }\end{array}$ & $\begin{array}{l}\text { You can do it properly or you can have a quick } \\
\text { scamper through it and not find anything (GP04). }\end{array}$ \\
\hline Skill-set workability & $\begin{array}{l}\text { Implementation was hindered when practices } \\
\text { didn't allocate adequate resources and time, } \\
\text { or when time was allocated but not protected. } \\
\text { The vast majority of clinician reviewers had the } \\
\text { necessary skills and experience to perform trigger } \\
\text { reviews. }\end{array}$ & $\begin{array}{l}\text { Time's the biggest killer. I think every practice could } \\
\text { open twenty-four hours a day and still not have time. } \\
\text { Every single thing that comes out: 'we'll get the } \\
\text { practice nurse to do it' but just how thin do you get } \\
\text { spread? (PN08). }\end{array}$ \\
\hline
\end{tabular}

GP, general practitioner; NPT, normalisation process theory; PSIs, patient safety incidents; QOF, quality and outcomes framework; TRM, trigger review method.

Cognitive participation: establishing a community of practice around the TRM

The initial work that was required to implement the TRM in practices was mainly done by GPs (table 4). They were motivated to undertake the work because of expressed interests in the quality of care they deliver and a desire to proactively identify and reduce potential safety threats. These 'champions' subsequently enrolled other members of their practice team to conduct TRMs using one of two strategies. The first and most common strategy was to assign specific responsibilities or tasks to individual team members. Most of the PNs, managers and

Table 6 Reflexive monitoring factors that facilitated or hindered TRM implementation

\begin{tabular}{lll}
\hline NPT components & Factors & Selected verbatim quotes \\
\hline Systematisation & $\begin{array}{l}\text { The simple, one-page data collection template } \\
\text { facilitated implementation by providing a clear, } \\
\text { structured format and electronic data collection. }\end{array}$ & $\begin{array}{l}\text { The form's helpful although it's perhaps a reporting } \\
\text { (GPorces you down the route of making you think }\end{array}$
\end{tabular}

Reconfiguration The TRM was intentionally designed to be flexible, which facilitated its implementation.

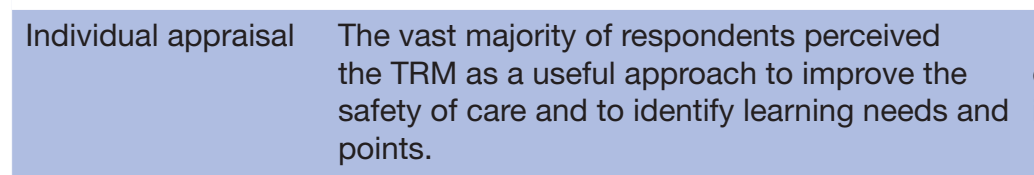
useful approach to further improve the quality and safety the care in the general practice setting.
So I changed it [the TRM trigger order] to: High

Priority, New Allergy, Investigations and then the Consultations and the Docman [correspondence] ehm Repeat medication at the very end. I found that was the quickest way for me to get through the triggers (PN01).

[We] got some really good outcomes from it: a couple of SEAs and an audit... There's learning for the system in there, so worthwhile, definitely worthwhile (GP04).

I like this [the TRM] as a kind of start. Here's something we can do regularly that can actually show us how good we are or how bad we are or areas that we need to work at or where we need to go (PM03).

I think it's more valuable than QOF QP to be honest. I think it is looking internally you know $-I$ think it has a value... it's just kind of embedding a culture within a practice (GP08).

NPT, normalisation process theory; QOF, quality and outcomes framework; TRM, trigger review method. 
administrative staff were recruited in this way. The second strategy was to recruit team members opportunistically when they expressed an interest in participation, which is how most GP colleagues within participating practices were recruited. Perhaps unsurprisingly then, GPs were more motivated to implement the TRM compared with PNs-at least initially.

GP trainees, inexperienced PNs and some salaried GPs were able to detect and learn from PSIs but their attempts to improve care were typically aimed at individual or small groups of patients. In contrast, GP partners and experienced PNs were able to disseminate learning points and act to improve care at practice and regional levels through their leadership roles and because of their ability to positively influence the rest of their team. However, a few participants were opposed to sharing the trigger review findings with anyone outside their practice team because of concerns that the data may be misinterpreted.

Factors that helped to legitimise the TRM facilitated its successful implementation. Participants felt justified in allocating additional time and resources to implement the TRM because of its inclusion in the QOF. They also perceived it as an acceptable professional activity because of its QI relevance to medical appraisal and GP specialty training. In addition, the endorsement of the TRM by their peers and professional organisations, such as the Royal College of General Practitioners (RCGP), helped to justify their participation and increased their willingness to continue using the TRM.

\section{Collective action: the work of enacting the TRM and integrating it with existing practices and contexts}

Implementation of the TRM was facilitated when reviewers detected PSIs quickly and the PSIs were unambiguous and perceived as serious, preventable and originating in primary care (table 5). The small minority of reviewers who were unable to detect a single PSI or only detected a few PSIs of low severity typically perceived this as an important barrier to the TRM's use. However, some reviewers alternatively interpreted 'finding nothing' as evidence for safe, high quality care in the clinical area being scrutinised.

Implementation of the TRM was facilitated when practices allocated adequate resources and sufficient time for clinicians to conduct trigger reviews without interruptions. While most practices allocated at least some protected time for TRM work, it was seldom adequate or uninterrupted. As a result, some reviewers reported that they conducted the reviews during their leisure time or in-between other tasks. Most reviews were interrupted because of urgent clinical tasks. Some reviewers were aware of a constant feeling of other tasks 'piling up' and a compulsion to check their workload, which distracted them from completing the trigger reviews.

The personal and professional characteristics of the clinician reviewers strongly influenced the implementation of the TRM. Experienced, enthusiastic clinicians who were motivated and able to critically reflect on the review process and how the detected PSIs may impact on care delivery and practice systems were more likely to report successfully implementing the TRM. They explained that applying the TRM in a 'tick box' manner reduced its effectiveness. While this was not considered an issue for the practice teams in this study, the participants were concerned that a substantial minority of other practices might adopt this approach in practice. Therefore, while most participants thought that incentivising the TRM through its inclusion in QOF was the key factor determining its uptake in the wider general practice community, they also expressed concern that a superficial, tick box approach would reduce its potential usefulness.

A substantial minority of practices nurses were initially uncertain whether they would be able to apply the TRM successfully. Some clinicians also lacked confidence in the validity of their early findings or the findings of other reviewers. Despite these misgivings, most PNs were able to detect PSIs, share the findings with their teams and recommend or make specific improvements within their practices. The confidence of all the participants in the TRM and their own skills and findings increased with time and experience, which helped facilitate its successful implementation.

\section{Reflexive monitoring: the work of adapting and evaluating the TRM}

Many participants identified the flexibility of the TRM, adapting it according to specific practice or reviewer requirements, as an important facilitating factor for its successful implementation (table 6). However, only two clinicians modified the method, the changes were minor and did not affect the outcomes.

Most participants perceived the TRM as a useful approach to improve the care they delivered to their patients, and for general practice in its wider sense. They also recognised its potential for identifying learning needs and points, encouraging reflection and raising awareness of potential safety threats. For these reasons, the TRM was considered to have equal or more value than existing QI methods. However, while the TRM's perceived usefulness was identified as an important facilitator for its implementation and was felt to increase the likelihood of it being used again in the future, all respondents were clear that evidence of its usefulness, while important, was insufficient in itself to ensure normalisation into routine practice. Successful normalisation would also require contextual integration, adequate protected time and additional resources.

\section{DISCUSSION}

We identified four main factors that facilitated or hindered the implementation of the TRM in Scottish general practice. The first factor was whether the amount of time and resources allocated to conduct trigger reviews were sufficient to enable implementation. The second factor was integration of the TRM in an established, national 
initiative (the QOF). This was a particularly important enabler, as it provided a financial incentive and professional justification for clinicians to implement the TRM. The third factor was the characteristics of the clinician reviewers. Implementation was facilitated by experienced clinicians with leadership roles in their practice teams. The fourth factor was the perceptions of the participants of the TRM, informed by their own practical experiences of using it. Implementation was facilitated if they understood it as acceptable, feasible and useful.

Practical implications and comparison with existing literature Devlin et $a l^{49}$ recently identified three key areas for researchers and policymakers to proactively consider for future, large-scale improvement initiatives if they are to be successfully implemented and normalised. They are: time; what the authors refer to as 'readiness', which is the product of resources and clinician engagement; and information technology. An earlier systematic literature review about the influence of context on QI in healthcare identified a slightly larger number of important 'success' factors: senior leadership; organisational culture; information systems; previous experience of $\mathrm{QI}$; clinician engagement; and resources. ${ }^{50}$ Braithwaite et a $a{ }^{1}$ identified eight comparable factors that determine implementation outcomes: preparing for change; capacity for implementation-setting; capacity for implementation-people; types of implementation; resources; leverage; sustainability; and desirable implementation enabling features.

The evidence from this study and the wider implementation science literature therefore suggest that a small number of specific factors are instrumental in facilitating or hindering the implementation of most, if not all, complex healthcare interventions. These factors can be identified, described and understood and are amenable to intervention. It is important for policymakers, healthcare professionals and researchers to proactively consider these factors when they are designing, implementing and evaluating new initiatives.

Providing frontline clinicians and staff with validated improvement methods and tools, education and training and 'expert' support are examples of important factors that are often included in improvement initiatives. However, they are insufficient to reliably improve care or change systems without the visible support of senior leaders and allocation of adequate resources and time. ${ }^{42495253}$ This helps to explain why implementation of the TRM was greatly facilitated by its inclusion in an established, national Framework-it clearly demonstrated senior leadership support and provided additional resources through financial incentives. While the need for allocating sufficient resources may seem self-evident, many improvement interventions receive no funding or funding for the implementation stage only, and even then the initial investments may be inadequate. ${ }^{42}$ It is therefore unsurprising than many interventions fail to become normalised despite evidence of their usefulness.

\section{Strengths and limitations of this study}

A unique strength of this study is that it is the first known attempt to investigate how the TRM is implemented in primary care by exploring the perceptions of clinicians and their general practice teams. A second strength is the use of a validated theoretical framework, which is recommended for research in the discipline of implementation science. ${ }^{37} \mathrm{~A}$ third strength is that the perceptions and experiences of the three different staff groups that were critical to the successful implementation of the TRM were considered. Because practices nurses also performed trigger reviews, the 'nursing' and 'medical' experiences and views could be compared. However, we found that the perceptions of the participants were highly congruent and independent of their roles and experience. A fourth strength is the different characteristics of participating practices, that is, training and non-training; semirural to urban locations and small to large patient populations.

The study has at least three limitations. The sampling strategy was a pragmatic choice and this group of volunteers may therefore not be representative of general practices in Scotland or other countries in the UK. However, thematic saturation was achieved and, in our opinion, more interviews would not have materially strengthened the main findings. Applying a theoretical framework to data raises potential concerns that researchers may be constrained by theory and miss important findings, or alternatively may 'shoe horn' data into existing themes. However, our experiences were similar to those of other researchers, which is that very little data fell outside the NPT framework, and the data that did were either too diffuse to be meaningful or did not directly relate to the main study aims. ${ }^{44}$ The third limitation is potential researcher bias. The analysis of qualitative data is inevitably influenced by the previous experiences and other characteristics of the researchers. A concerted effort was made to account for subjectivity through a combination of reflection, rigorous application of a transparent analysis process and by evaluating the veracity of the results against the international literature.

\section{Next steps}

Patient safety remains a high priority in primary care worldwide. The National Quality Strategy specifies six healthcare priorities for the USA, of which the first is to 'make care safer'. ${ }^{55}$ One the main levers they use to achieve this aim is 'learning and technical assistance', that is, offering training and improvement tools.

In Scotland, GPs can submit trigger review findings as part of the mandatory QI activity evidence required for appraisal purposes. ${ }^{56}$ The 'National Framework for Quality and GP Clusters' (see Box 1) identified a role for the TRM and recommends 'structured review of high risk patient records' as one of nine validated safety improvement tools to the new Clusters. ${ }^{57}$ The RCGP has included the method in their patient safety toolkit as a potential evidence source for supporting medical revalidation of GPs in the UK. ${ }^{58}$ In England, Clinical 
Commissioning Groups were established in 2013 with two important but distinct roles: to commission secondary and community care services for their populations; and to support QI in general practice. ${ }^{59}$ While the first role has received most attention to date, the second role is equally important and a legal duty that will require greater clinical engagement and validated tools, such as the TRM. ${ }^{6061}$

The Australian Commission on Safety and Quality in Healthcare started a consultation in October 2017 as a first step in developing a national approach to support improvements in patient safety and quality in primary care. ${ }^{62}$ Although the consultation is ongoing, it seems reasonable to assume that any approach will have to include the 31 primary health networks that were established in 2015 to better integrate care and to ensure that all Australian patients 'receive the right care in the right place at the right time ${ }^{, 63}$ The approach will also require a cohesive implementation strategy, validated tools such as the TRM and allocation of adequate resources. The 'medical homes' initiative provides a practical example of how existing funding arrangements can be adapted at the federal level to encourage a more flexible approach to healthcare. ${ }^{64}$

All these examples demonstrate a need for validated tools. However, it is unclear whether any organisation has fully considered or comprehensively addressed the main factors that are known to facilitate or hinder the effective, routine use of improvement methods. The pressing questions are therefore whether and to what extent the use of improvement tools like the TRM will become normalised in specific healthcare settings like general practice, and how this process can best be supported.

\section{CONCLUSION}

We identified four important factors that facilitated the implementation of the TRM in Scottish general practice. The factors are comparable with the wider implementation science literature, suggesting that a small number of specific factors are instrumental in facilitating or hindering the implementation of most, if not all, complex healthcare interventions. These factors can be identified, described and understood through theoretical frameworks such as NPT and are amenable to intervention. This may allow researchers and policymakers to proactively identify and address the main factors that are known to facilitate or hinder the implementation and normalisation of improvement initiatives. Normalisation of the TRM therefore seems likely if the following factors could be guaranteed: clinicians have the necessary knowledge and skills to apply the TRM effectively; there is senior leadership support for the TRM at practice and national levels; adequate resources and time are provided to conduct trigger reviews; and it is formally integrated into existing professional activities, government policies and national improvement initiatives.
Contributors CdW: concept, study design, data analysis, codevelopment and critical review of manuscript. CAO: data analysis. PB and CAO: concept, study design, codevelopment and critical review of manuscript, study guarantors.

Funding The authors have not declared a specific grant for this research from any funding agency in the public, commercial or not-for-profit sectors.

Competing interests None declared.

Patient consent for publication Not required.

Ethics approval The study was submitted to and approved by the Glasgow University's College of Medicine, Veterinary and Life Science's Ethical Committee, reference number 2012054. All participants provided written, informed consent before the interviews were conducted.

Provenance and peer review Not commissioned; externally peer reviewed.

Data availability statement Data are available upon reasonable request.

Open access This is an open access article distributed in accordance with the Creative Commons Attribution Non Commercial (CC BY-NC 4.0) license, which permits others to distribute, remix, adapt, build upon this work non-commercially, and license their derivative works on different terms, provided the original work is properly cited, appropriate credit is given, any changes made indicated, and the use is non-commercial. See: http://creativecommons.org/licenses/by-nc/4.0/.

\section{REFERENCES}

1. Bowie P, McKay J, McNab D, et al. The past, present and future of patient safety education and research in primary care. Educ Prim Care 2016;27:3-9.

2. Vincent C, Neale G, Woloshynowych M. Adverse events in British hospitals: preliminary retrospective record review. BMJ 2001;322:517-9.

3. Francis R. Report of the Mid Staffordshire NHS Foundation trust public inquiry: Executive summary. London The House of Commons; 2013.

4. Panesar SS, deSilva D, Carson-Stevens A, et al. How safe is primary care? A systematic review. BMJ Qual Saf 2016;25:544-53.

5. Carson-Stevens A, Hibbert P, Williams $\mathrm{H}$, et al. Characterising the nature of primary care patient safety incident reports in the England and Wales national reporting and learning system: a mixed-methods agenda-setting study for general practice. Health Serv Deliv Res 2016;4:1-76.

6. National Patient Safety Agency. What is a patient safety incident? 2011. Available: http://www.npsa.nhs.uk/nrls/reporting/what-is-apatient-safety-incident/ [Accessed 18 Feb 2019].

7. Sarkar U. Tip of the iceberg: patient safety incidents in primary care. BMJ Qual Saf 2016;25:477-9.

8. Cooper A, Chuter A. Patient safety research in primary care: where are we now? Br J Gen Pract 2015;65:622-3.

9. Esmail A, Valderas JM, Verstappen W, et al. Developing a research agenda for patient safety in primary care. background, aims and output of the LINNEAUS collaboration on patient safety in primary care. Eur J Gen Pract 2015;21 Suppl:3-7.

10. The Health Foundation. Learning report: Safer Patients Initiative Lessons from the first major improvement programme addressing patient safety in the UK. Report No.: 1. London Health Foundation; 2011.

11. Dingwall R, Palmer C, Rowley E, Waring J, Murcott T. PS050: synthesis of the outputs of research commissioned under the patient safety research portfolio. Nottingham University of Nottingham Institute for Science and Society; 2009.

12. The Health Foundation. Safer Patients Network: Evaluation - an independent evaluation of the Safer Patients Network improvement programme. London Health Foundation; 2013.

13. Healthcare Improvement Scotland. SPSP Acute Adult - end of phase report. Report No.: 1. Scotland Healthcare Improvement Scotland; 2016.

14. Healthcare Improvement Scotland. SPSP primary care. Scotland Healthcare Improvement Scotland; 2016.

15. Bowie P, Halley L, Blamey A, et al. Qualitative evaluation of the safety and improvement in primary care (SIPC) pilot collaborative in Scotland: perceptions and experiences of participating care teams. BMJ Open 2016;6:e009526.

16. de Wet C, Bowie P. The preliminary development and testing of a global trigger tool to detect error and patient harm in primary-care records. Postgrad Med J 2009;85:176-80.

17. De Wet C, Bowie P. Screening electronic patient records to detect preventable harm: a trigger tool for primary care. Qual Prim Care $2011 ; 19: 115-25$. 
18. de Wet C, Spence W, Mash R, et al. The development and psychometric evaluation of a safety climate measure for primary care. Qual Saf Health Care 2010;19:578-84.

19. de Wet C, McKay J, Bowie P. Combining QOF data with the care bundle approach may provide a more meaningful measure of quality in general practice. BMC Health Serv Res 2012;12:351.

20. de Wet C, Black C, Luty S, et al. Implementation of the trigger review method in Scottish general practices: patient safety outcomes and potential for quality improvement. BMJ Qual Saf $2017 ; 26$.

21. Schildmeijer K, Nilsson L, Perk J, et al. Strengths and weaknesses of working with the global trigger tool method for retrospective record review: focus group interviews with team members. BMJ Open 2013;3:e003131.

22. Weaver SJ, Lubomksi LH, Wilson RF, et al. Promoting a culture of safety as a patient safety strategy. Ann Intern Med 2013;158:369.

23. Verstappen W, Gaal S, Esmail A, et al. Patient safety improvement programmes for primary care. review of a Delphi procedure and pilot studies by the LINNEAUS collaboration on patient safety in primary care. Eur J Gen Pract 2015;21 Suppl:50-5.

24. Lavallée JF, Gray TA, Dumville J, et al. The effects of care bundles on patient outcomes: a systematic review and meta-analysis. Implement Sci $2017 ; 12$.

25. Shojania KG, Thomas EJ. Trends in adverse events over time: why are we not improving? BMJ Qual Saf 2013;22:273-7.

26. Woloshynowych M, Neale G, Vincent C. Case record review of adverse events: a new approach. Qual Saf Health Care 2003;12:411-5.

27. Brennan TA, Leape LL, Laird NM, et al. Incidence of adverse events and negligence in hospitalized patients: results of the Harvard medical practice study I. 1991. Qual Saf Health Care 2004;13:145-51.

28. Wilson RM, Runciman WB, Gibberd RW, et al. The quality in Australian health care study. Med J Aust 1995;163:458-71.

29. Baker GRet al. The Canadian adverse events study: the incidence of adverse events among hospital patients in Canada. Can Med Assoc J 2004:170:1678-86.

30. Davis P, Lay-Yee R, Briant R, et al. Adverse events in New Zealand public hospitals I: occurrence and impact. $N Z$ Med $J$ 2002;115:U271.

31. Finch TL, Mair FS, O'Donnell C, et al. From theory to 'measurement' in complex interventions: methodological lessons from the development of an e-health normalisation instrument. BMC Med Res Methodol 2012;12.

32. Dixon-Woods M, McNicol S, Martin G. Ten challenges in improving quality in healthcare: lessons from the health Foundation's programme evaluations and relevant literature. BMJ Qual Saf 2012;21:876-84.

33. Davidoff F, Dixon-Woods M, Leviton L, et al. Demystifying theory and its use in improvement. BMJ Qual Saf 2015;24:228-38.

34. Kleinman LC, Dougherty D. Assessing quality improvement in health care: theory for practice. Pediatrics 2013;131 Suppl 1:S110-S119.

35. Eccles MP, Armstrong D, Baker R, et al. An implementation research agenda. Implement Sci 2009;4.

36. Grol RPTM, Bosch MC, Hulscher MEJL, et al. Planning and studying improvement in patient care: the use of theoretical perspectives. Milbank Q 2007;85:93-138.

37. Craig P, Dieppe P, Macintyre S, et al. Developing and evaluating complex interventions: the new medical Research Council guidance. BMJ 2008;337.

38. Allen D, Braithwaite J, Sandall J, et al. Towards a sociology of healthcare safety and quality. Sociol Health IIIn 2016;38:181-97.

39. Marshall M, de Silva D, Cruickshank L, et al. What we know about designing an effective improvement intervention (but too often fail to put into practice). BMJ Qual Saf 2017;26:578-82.

40. Nilsen P. Making sense of implementation theories, models and frameworks. Implement Sci 2015;10.

41. O'Donnell CA, Mair FS, Dowrick C, et al. Supporting the use of theory in cross-country health services research: a participatory qualitative approach using normalisation process theory as an example. BMJ Open 2017;7:e014289.

42. Bamford C, Heaven B, May C, et al. Implementing nutrition guidelines for older people in residential care homes: a qualitative study using normalization process theory. Implement Sci 2012;7.

43. May CR, Finch TL, Cornford J, et al. Integrating telecare for chronic disease management in the community: what needs to be done? BMC Health Serv Res 2011;11.
44. Gallacher K, May CR, Montori VM, et al. Understanding patients' experiences of treatment burden in chronic heart failure using normalization process theory. Ann Fam Med 2011;9:235-43.

45. May C, Finch T. Implementing, embedding, and integrating practices: an outline of normalization process theory. Sociology 2009;43:535-54.

46. O'Brien BC, Harris IB, Beckman TJ, et al. Standards for reporting qualitative research: a synthesis of recommendations. Acad Med 2014;89:1245-51.

47. Scottish Government. NHS boards: Scottish government, 2018 Available: http://www.gov.scot/Topics/Health/NHS-Workforce/NHSBoards [Accessed 18 Feb 2019].

48. Ritchie J, Spencer L. Qualitative data analysis for applied policy research. In: Bryman A, Burgess R, eds. Analyzing qualitative data. London: Routledge, 1994: 173-94.

49. Devlin AM, McGee-Lennon M, O'Donnell CA, et al. Delivering digital health and well-being at scale: lessons learned during the implementation of the Dallas program in the United Kingdom. J Am Med Inform Assoc 2016;23:48-59.

50. Kaplan HC, Brady PW, Dritz MC, et al. The influence of context on quality improvement success in health care: a systematic review of the literature. Milbank Q 2010;88:500-59.

51. Braithwaite J, Marks D, Taylor N. Harnessing implementation science to improve care quality and patient safety: a systematic review of targeted literature. Int J Qual Health Care 2014;26:321-9.

52. Franx G, Oud M, de Lange J, et al. Implementing a stepped-care approach in primary care: results of a qualitative study. Implement Sci 2012;7.

53. Gunn JM, Palmer VJ, Dowrick CF, et al. Embedding effective depression care: using theory for primary care organisational and systems change. Implement Sci 2010;5.

54. McEvoy R, Ballini L, Maltoni S, et al. A qualitative systematic review of studies using the normalization process theory to research implementation processes. Implement Sci 2014;9.

55. Agency for Healthcare Research and Quality. The National quality strategy: fact sheet, 2018. Available: https://www.ahrq.gov/ workingforquality/about/nqs-fact-sheets/fact-sheet.html [Accessed 18 Feb 2019]

56. Scotland NEf. Scottish Online Appraisal Resource (SOAR): Domain 2 - Safety and Quality: Trigger Review Documentation Scotland Scotland: NHS Education for Scotland, 2017. Available: http:// www.appraisal.nes.scot.nhs.uk/i-want-access-to/toolkits/scottishgp-appraisal-toolkit/domain-2/trigger-review-documentation.aspx [Accessed 11 Jan 2017].

57. Scottish Government. Improving together: a national framework for quality and GP clusters in Scotland: 2017. Report No.: 1. Scotland; 2017.

58. Practitioners RCoG. Patient safety toolkit for general practice: RCGP, 2017. Available: http://www.rcgp.org.uk/clinical-and-research/ toolkits/patient-safety.aspx [Accessed 11 Jan 2017].

59. NHS England. Clinical commissioning groups England, 2018. Available: https://www.england.nhs.uk/ccgs/ [Accessed 18 Feb 2019].

60. Naylor C, Curry N, Holder H, Ross S, Marshal L, Tait E. Clinical commissioning groups: supporting improvement in general practice?. Report No.: 1. London King's Fund, Nuffield Trust; 2013.

61. Robertson R, Holder H, Ross S, Naylor C, Machaqueiro S. Clinical commissioning: GPs in charge? London King's Fund, Nuffield Trust; 2016.

62. Australian Commission on Safety and Quality in Health Care. Patient safety and quality improvement in primary care. Sydney Australian Commission on Safety and Quality in Health Care; 2017.

63. Booth M, Hill G, Moore MJ, et al. The new Australian primary health networks: how will they integrate public health and primary care? Public Health Res Pract 2016;26.

64. Australian Centre for the Medical Home. The medical home, 2017. Available: http://medicalhome.org.au/ [Accessed 18 Feb 2019].

65. Lester H, Campbell S. Developing Quality and Outcomes Framework (QOF) indicators and the concept of 'QOFability'. Qual Prim Care 2010;18:103-9.

66. Information Services Division Scotland. Quality and outcomes framework: general practice, 2016. Available: http://www. isdscotland.org/Health-Topics/General-Practice/Quality-AndOutcomes-Framework/ [Accessed 18 Feb 2019].

67. BBC News: Scotland politics. 'Outdated' QOF GP payment system scrapped in Scotland, 2015. Available: http://www.bbc.com/news/ uk-scotland-scotland-politics-34419123 [Accessed 18 Feb 2019]. 